\title{
The Usage of Data Repositories: The Case of MAOR
}

\section{Anat Cohen Tel Aviv University Tel Aviv, Israel}

anatco@post.tau.ac.il

\author{
Eli Shmueli \\ MEITAL \\ Israel
}

eli@mail.iucc.ac.il

\author{
Rafi Nachmias \\ Tel Aviv University \\ Tel Aviv, Israel
}

\begin{abstract}
MAOR (Meta-data and Object Repository) is a national Israeli repository of online learning object meta-data. MAOR serves as a major online learning resource repository, containing materials for both K-12 and Higher Education and enabling teachers to share, reuse, and remix modular learning objects. This paper describes the MAOR repository and the stages of its establishment. Subsequently the growth of the repository analysis is presented, focusing on the learning objects characteristics, contribution rate, and contributors' profile. The outcomes of the analysis indicated that learning objects from different disciplines (especially Science and Technology, Social Science, and Humanities) were contributed to the MAOR repository. Varied types of learning objects were found, representing different types of content and activities with different goals aimed at diverse target audiences. The majority of resources were contributed by educational institutions, mainly academic institutions and content providers. Although MOAR was established on the basis of the MERLOT model, its contributors' profile is different due to the fact that most of the contributors are the authors. Besides, the findings that are set out in this paper also show distinction in contribution rate between the institutions that consider the contribution of materials as part of their policy and institutions that do not.
\end{abstract}

Keywords: Repository, Learning Object, Open Access, Open Educational Resources, Distance Learning.

\section{Introduction}

With the expansion of technological possibilities in education in general, and the integration of web-based learning tools in particular, many Israeli lecturers have begun to integrate web applications in order to demonstrate and enrich their learning material. Many of them set up sites for

Material published as part of this publication, either on-line or in print, is copyrighted by the Informing Science Institute. Permission to make digital or paper copy of part or all of these works for personal or classroom use is granted without fee provided that the copies are not made or distributed for profit or commercial advantage AND that copies 1) bear this notice in full and 2) give the full citation on the first page. It is permissible to abstract these works so long as credit is given. To copy in all other cases or to republish or to post on a server or to redistribute to lists requires specific permission and payment of a fee. Contact Publisher@InformingScience.org to request redistribution permission. their courses, take part in setting up or use local databases, and integrate applications into their lesson plans. This includes social media tools (wiki, blogs, social networks, etc.), educational software, simulations, animations, two- and three-dimensional models and more. Many of these lecturers take part in establishing local and institutional open repositories and use them in their instruction.

Editor: Alex Koohang

An earlier, shorter version of this paper was presented at the Chais conference 2011, in Raanana, Israel, and included in Y. Eshet-Alkalai, A. Caspi, S. Eden, N. Geri, \& Y. Yair (Eds.), Proceedings of the Chais conference on instructional technologies research 2011: Learning in the technological era. Raanana: The Open University of Israel.

http://www.openu.ac.il/research center/chais2011/papers.html 
Learning object repositories provide a platform for sharing educational resources on the Web, and most of them provide some mechanisms for building community dynamics around their resources, such us MERLOT communities (MERLOT, 2011). A learning material repository becomes more than a portal when it enables users to find learning objects and digital resources that can be reused to support learning (Wiley, 2000). That is to say, the purpose of a digital repository is not only to store, catalog, and distribute learning objects, but also to allow their sharing and reuse (Duncan, 2003). Searching, finding, and reusing learning objects become possible through setting meta-data. Meta-data (data about data) is descriptive information about the resource that describes the learning object and is required in order to find and reuse it. Therefore, it is essential that each learning object has consistent metadata fields.

In recent years, trends of cooperation and using online learning materials have grown considerably stronger, with emphasis on the openness of materials and their availability on the Web (Hylén, 2006; World Forum of UNESCO Chairs, 2002). These trends influenced the development of the new repositories. While many learning objects repositories were stand-alone sites and functioned much like websites in that they contained a web-based user interface, a search mechanism and a category listing, recently another major class of learning object repositories is emerging that functions more like a database attached to another product. An LCMS (Learning Content Management System), for example, may contain a learning object repository intended for its exclusive use. The first type of repositories usually contains both the learning objects and learning object metadata; the latter repositories usually contain metadata only. In that case, the learning objects themselves are located at a remote location and the repository is used as a tool to locate learning objects. In the former, the repository may be used to both locate and deliver the learning object (Downes, 2004).

Despite the many advantages inherent in online repositories and in millions of sites containing materials that can help the process of teaching (Schell \& Burns, 2002), there is a concern that the abundance of information presented will lead to time wasted in search of information and difficulty in the absence of appropriate tools for evaluating the quality and reliability of the information and its management (Taibi, Gentile, \& Seta, 2005). Moreover, these repositories offering accessibility and availability of learning objects are not always easy to navigate due to the lack of a uniform system and learning object catalog (Nash, 2005). To benefit from these repositories and to help locate these learning materials and reach their optimal utilization, a national Israeli learning objects database has been established. It was given the name MAOR: Meta-data and Object Repository.

The study presented in this paper is part of a wider research that investigates the phenomenon of central portals connected to multiple learning object repositories. These portals contain only the object meta-data and allow users access to learning materials stored and dispersed in several online repositories. This study focuses on the MAOR repository and the learning objects that were cataloged in it. In this paper we will first briefly describe the MAOR repository and its establishment process. Subsequently we will present preliminary findings regarding (a) the learning objects that were contributed to the MAOR repository, referring to the discipline to which they belong, the different types of contacts and activities that indicate their instructional goals, their target audiences, and their technical formats, (b) the expansion rate of the repository, which will reflect the publication process and (c) the identity of learning objects contributors.

\section{Background}

In the last decade, a continuous growth is observed in the number of learning resources available in learning object repositories (The Directory of Open Access Repositories - OpenDOAR, 2011). This growth supports the trend of openness and sharing in these resources, emphasizing the openness of the materials and their availability on the web as Open Educational Resources (OER). 


\section{Learning Object Repositories}

Digital repositories are systems that enable the storage, discovery, and retrieval of meta-data and/or electronic objects stored at a local or distributed level (The JORUM Team, 2006). More specifically, a Learning Object Repository (LOR) is a system that manages access to reusable learning content, as it has been defined by several authors (Monge, Ovelar \& Azpeitia, 2008). The new trends of openness and sharing within learning communities in the Web 2.0 era allow rethinking about the design of new models for learning object repositories, which reflect the characteristics of learning and knowledge that are social, personal, flexible, dynamic, and distributed in nature.

Learning objects (LOs) are often defined as digital entities that can be used and reused in the process of learning and education and are considered by many as the cornerstones for the widespread development and adoption of e-learning initiatives (Cechinel, Sanchez-Alonso \& GarciaBarriocanal, 2011). Learning objects are elements of a new type of computer-based instruction grounded in the object-oriented paradigm of computer science. Object-orientation highly values the creation of components (called "objects") that can be reused (Dahl \& Nygaard, 1966) in multiple contexts. This is the fundamental idea behind learning objects: instructional designers can build small (relative to the size of an entire course) instructional components that can be reused a number of times in different learning contexts. Additionally, learning objects are generally understood to be digital entities deliverable over the Internet, meaning that any number of people can access and use them simultaneously (as opposed to traditional instructional media, such as an overhead or video tape, which can only exist in one place at a time). Those who incorporate learning objects can collaborate on and benefit immediately from new versions. These are significant differences between learning objects and other instructional media that have existed previously (Wiley, 2000). Friesen (2009) points out modularity as a technological and design attribute for the object and its content, with emphasis on the "self-contained," "building block," or "objectoriented" nature of the technology.

The ability to transfer information among repositories and enable reuse of learning objects comes about by setting meta-data. Meta-data (data about data) is descriptive information about the resource that describes the learning object and is critical for its sharing and reuse. Therefore, it is essential that each learning object has consistent meta-data fields. The ability to find learning materials, which are accompanied by meta-data, allows the reuse and re-construction of learning materials. Thus a variety of learning processes can be created with adaptation to the needs of the student and the learning objective.

Learning object repositories provide a platform for the sharing of educational resources on the Web, and most of them provide some mechanisms for building community dynamics around their resources. The community dimension and its social dynamics have been found to be an aspect important for the success of these repositories (Sicilia, Garcia-Barriocanal, Sanchez-Alonso \& Cechinel, 2010). Repositories also provide some tools that improve user experience. Personal folders, features that allow users to "bookmark" interesting items, are among the most frequently used tools within studied cases. In Curriculum Online, these lists of resources or educational contents and related information can be sent by mail. OER Commons users can publish their selections in their portfolio, a feature that in fact represents a recommender system that enables a sort of social information retrieval system (Monge, et al., 2008).

Many repositories are effectively created by their users and offer tools that enable users to give their opinion on objects, whether by vote, frequency of use, or peer review. Using these tools, a user may learn of an object's quality or receive other users' recommendations of the best ways to use a resource. User involvement and exchange of information between learners creates a learning community that shares information of great value. These communities are created across bor- 
ders and add a great deal of informal knowledge. The exchange of information and recommendations among participants increases the potential to benefit from the knowledge of others. In the process of integrating online learning objects as building blocks, the combination of different valuated learning objects offers the learner an effective learning process of high quality. Community members involved in the repository environment increase the motivation to use the learning materials and to support the community by passing on valuable informal knowledge to other users (Shmueli \& Cohen, 2011).

In a university setting, a repository may provide a place for faculty work, student theses and dissertations, e-journals, datasets, and so on. Whatever the particular focus of the university repository is, to be successful it must be filled with scholarly work of enduring value that is searched and cited. Based on the number of institutional repositories established over the past few years, the repository service appears to be quite attractive and compelling to institutions. Repositories provide an institution with a mechanism to showcase its scholarly output, centralize and introduce efficiencies to the stewardship of digital documents of value, and respond proactively to the escalating crisis in scholarly communication (Foster \& Gibbons, 2005).

\section{Different Types of Learning Object Repositories}

Three major types of LOR can be identified according to the distribution and sharing models for LO (Shmueli, Reisman, \& Sperling, 2010):

A. Local repositories, usually institutional collections, which contain learning objects and meta-data. These repositories can be found in many institutions that develop and store learning materials for the higher education community and in educational institutions in general such as the Pe'er project (Tal-Elhasid, Yair, \& Meishar-Tal, 2009), MIT Open Courseware (Abelson, 2008), and TAU EVNU (Nachmias, Leiba, \& Ram, 2007). These repositories were established to serve local communities and answer specific pedagogical needs. Learning materials in them were developed according to learners' needs in order to improve the process of learning. These repositories are normally designed by experts aware of the needs of the institution and according to learners' needs. Development of learning objects is usually undertaken by a pedagogical development team and a professional team. Production of this sort uses a substantial amount of the budget for development available to institutions or other public bodies and is, thus, usually kept on a small scale.

B. Major portals that are connected to multiple repositories. These portals allow access to learning materials stored in several online repositories, which contain only object metadata. Repositories such as MAOR (2011), MERLOT (Malloy \& Hanley, 2001) and Open Courseware Consortium (Taylor, 2007) contain only the meta-data and allow access to learning materials hosted in the connected repositories. The objects stored in these repositories are characterized according to international standards for learning objects metadata. The meta-data fields describe the object and the possibilities for its use, so that objects may be located using keywords, retrieved, and examined to see whether they suit learners' needs.

C. International associations and consortiums that enable the sharing of learning objects among repository networks worldwide. Consortiums such as Globe enable users to broaden their search between international repositories according to meta-data standards via means such as harvesting, Federate-Search, and sharing of learning objects. These consortiums' features, which characterize objects and include information fields describing materials, further expand the use of learning materials by retrieving these materials 
via modular construction of objects and their integration in new learning processes forms according to learners' needs.

\section{MAOR - Meta Data and Object Repository}

MAOR (Meta-data and Object Repository) is a national Israeli repository of online learning object meta-data. MAOR's goals are to assist in the locating of online educational resources that have undergone review and to utilize them for learning. MAOR offers interoperability between learning materials in repositories, both Israeli and worldwide, and grants access to high quality learning materials for the learning and teaching public. It is available and open to varied target audiences, such as institutes of education (Universities, Colleges, K-12, and professional training), public bodies, and individuals involved in teaching and learning in Israel, and enables easy and convenient sharing of learning objects. The repository contains meta-data about learning objects such as online courses, lecturer presentations, simulations, websites, video, audio, blogs, wikis, assignments, drilling, and quizzes. Furthermore, the repository provides tools for searching and locating objects to be used in learning frameworks. Content developers, 'peer review', and users' evaluations of the learning objects will also be included in the database.

MAOR was established in 2009 as a joint project of the Inter-University Computation Center (IUCC), the Israeli Chapter of the Internet Society (ISOC-IL), and the Israeli Ministry of Education and was supported by the planning and budgeting committee of the council for higher education in Israel. It was established in cooperation with MERLOT, an American learning object repository. MAOR allows access and contribution to MERLOT through a Hebrew interface. The first step in creating MAOR involved the adaptation of the MERLOT database to handle the Hebrew script, which is written from right to left. MERLOT was, therefore, converted to UTF-8. After the conversion, a Hebrew portal was built in order to enable Hebrew speakers to access the MERLOT database, which contains thousands of cataloged educational resources that have undergone peer review.

The MAOR repository was established in three stages:

1. Definition of an Israeli standard for meta-data of learning objects. The establishment of a national learning objects database requires the consolidation of principles for characterizing and defining an Israeli standard for learning object meta-data, with the intention that this definition will help create a common and uniform language for all the bodies active in this field in the State of Israel (academia, educational institutions, industry, and content providers). The work group, in which IUCC, the Israel Internet Association, and the Ministry of Education were represented, has defined the Israeli standard for characterizing learning objects - ISRACore. This standard is based on the LOM (Learning Object Metadata), which is accepted in Europe for metadata for learning objects. LOM is the standard of the IEEE Institute of Electrical and Electronics Engineers, Inc. The standard defines information about the object according to parameters, such as the definition of search fields, thesaurus for object characterization, addition possibilities, and corrections made after the object has been created (Barker \& Campbell, 2010). Other parts of the standard define the information envelope and how the list will be presented in XML. The parameters proposed by the standard assist in locating, evaluating, and sharing the learning resource. The resource's description can be adapted to meet various communities' needs. The adoption of the Israeli standard, ISRACore, by the organizations that are active in this field in Israel will assist in creating a common language for the use of various databases in Israel and worldwide and will, thus, expand the range of objects placed at the disposal of users in various frameworks. Additionally, the implementation of the standard will enable users in different sectors to find the learning objects most suitable 
for their needs more easily, to reuse resources that have already been developed, and to create new ones on the basis of existing content.

2. Construction of MAOR portal. An agreement was signed among the Inter-University Computation Center (IUCC), the Israeli Chapter of the Internet Society (ISOC-IL), the Israeli Ministry of Education, and MERLOT. Then, the adaptation of the MERLOT database to handle the Hebrew script, which is written from right to left, was needed. MERLOT was therefore converted to UTF-8. After the conversion, a Hebrew portal was built in order to enable Hebrew speakers to access the MERLOT database. As a result, MAOR allows access to MERLOT through a Hebrew interface, which contains tools for searching and locating learning objects. MERLOT is a free and open online community of resources designed primarily for faculty, staff, and students of higher education from around the world to share their learning materials and pedagogy. MERLOT is a leading edge, user-centered, collection of peer reviewed higher education, online learning materials catalogued by registered members and a set of faculty development support services. MERLOT's strategic goal is to improve the effectiveness of teaching and learning by increasing the quantity and quality of peer reviewed online learning materials that can be easily incorporated into faculty designed courses. MERLOT's activities are based on the creative collaboration and support of its Individual Members, Institutional Partners, Corporate Partners and Editorial Boards.

3. Development of a learning objects contribution system. A material contribution system was developed for MAOR, which enables all visitors to the site to join as MAOR members and add learning materials. In addition, institutions interested in contributing a large number of materials may add them to the repository with MEITAL's assistance. At this stage MAOR allows access and contribution to several online repositories such as MERLOT through a Hebrew interface. Additionally, a mechanism for peer review and expert review of learning materials was developed. Thus, the system enables users to state their own impressions regarding a learning object and their personal experiences in using that object. These impressions and evaluations may indicate the quality of an educational resource and assist users in integrating relevant material into lesson plans. These references by users enrich the information gathered on an object, its use, and its suitability for different audiences. This informal information joins the rest of the data collected in regard to learning objects and serves other users that wish to implement them in a learning process.

\section{Methodology}

This study is part of a wider research that investigates the phenomenon of central portals connected to multiple learning object repositories. These portals contain only the object meta-data and allow users access to the learning materials stored in several online repositories. This study focuses on the MAOR repository and the learning objects cataloged in it.

\section{Research Aims and Questions}

The aim of this study is to explore the MAOR repository from three points of view. The first is to characterize the learning objects presented in MAOR repositories; the second is to explore the expansion rate of the learning object in the repository, which will indicate the publication process; the third is to characterize the contributors to MAOR. In correspondence to this, this study provides answers to three main questions: (a) What kinds of learning materials are contributed to the repository MAOR, and what are their characters? (b) How do MAOR learning objects grow over time? (c) Who are the contributors? Are contributors also the authors of the published learning materials? 


\section{Research Field}

The study was initially conducted on the learning objects meta-data which were cataloged in the MAOR portal as of May 2011. These learning objects were contributed since October 2009, MAOR's public opening date $(N=3192)$. Next, the study focuses on 119 contributors of these learning objects. It is important to mention that, in the development stages of MAOR, significant activities were carried out to encourage the contribution of learning materials by higher education institutions and content providers and not by individual users.

\section{Method}

The MAOR repository accumulates a vast amount of educationally relevant information in its server's Web-logs, which is extremely valuable. A data mining tool has been developed during the establishment of the MAOR portal. This tool enables access to the server database and retrieval of data about the learning objects in the repository, pattern of usage, and data about the contributors. The data are extracted from the site's Web-logs and provide crucial information.

Addressing the research questions yields data on three levels: First, data regarding the learning objects that were cataloged in the MAOR repository were extracted from six main tables (objects, objects' category, objects' audience, objects' language, collections' details, and comments).

These data reflect the characteristics of the object: discipline, the content or activity type, target audience, and technical format. Second, data regarding the publication date of the learning objects was extracted from the action table. Third, data regarding the contributors of the repository were extracted from three main tables (users, user affiliation, and objects authors).

Analysis of MAOR included these data, which were collected automatically in MAOR's server and extracted from the site's web-log files through a web-mining tool in May 2011. Although it is possible to draw data regarding the objects cataloged in MAOR repository and MERLOT as well, this study will focus only on data about the items cataloged in MAOR

\section{Preliminary Findings}

\section{Learning Object Characteristics}

Addressing the first question of the study, the contributed learning objects in MAOR were characterized through data extracted from MAOR portal weblogs. Characteristics included the discipline that the objects belong to, the types of contents and activities that indicate their instructional goals, their target audiences, and their technical formats.

\begin{tabular}{|l|r|}
\hline \multicolumn{2}{|c|}{ Table 1: Learning object distribution according to discipline } \\
\hline \multicolumn{1}{|c|}{ DISCIPLINE } & NUMBER OF LEARNING OBJECTS \\
\hline Science and Technology & 1058 \\
\hline Social Sciences & 902 \\
\hline Humanities & 627 \\
\hline Business Management & 254 \\
\hline Arts & 178 \\
\hline Mathematics and Statistics & 80 \\
\hline Education & 87 \\
\hline Academic Support Services & 6 \\
\hline Total & $\mathbf{3 1 9 2}$ \\
\hline
\end{tabular}


Table 1 presents the distribution of the learning objects by discipline. Most learning objects belong to the discipline of Science and Technology (1058 objects), Social Sciences (902 objects), and Humanities (627 objects).

Varied types of contents and activities are included in the MAOR repository. These types indicate objects' different educational goals. Table 2 shows the distribution of content and activity types contributed to the repository. This table reveals that the most frequent resource type is the reference material, which consisted of information units (67.7\% of all learning objects). Reference material serves as a generic heading for informative textual learning objects that are not in the format of a published article. Many of the resources in MAOR, being public and not necessarily affiliated with established publications, are complementary or introductory in nature, in the form of summaries, articles that do not follow academic guidelines, lists, or cliff notes. These texts are normally categorized as reference material. Other types of content and activities, however, do not appear very frequently (e.g., $8.9 \%$ of the objects were assignments, $4.4 \%$ were animations). This finding indicates that the main purpose of these learning objects is content delivery, rather than interactivity and assessment.

\begin{tabular}{|c|c|c|}
\hline $\begin{array}{c}\text { CONTENT / ACTIVITY } \\
\text { TYPE }\end{array}$ & $\begin{array}{c}\text { NUMBER OF } \\
\text { LEARNING OBJECTS }\end{array}$ & $\begin{array}{c}\text { PRESENTAGE OF } \\
\text { ALL LEARNING } \\
\text { OBJECTS }\end{array}$ \\
\hline Reference Material & 2162 & $67.7 \%$ \\
\hline Assignment & 285 & $8.9 \%$ \\
\hline Open Journal/Article & 213 & $6.7 \%$ \\
\hline Collection & 150 & $4.7 \%$ \\
\hline Animation & 142 & $4.4 \%$ \\
\hline Online Course & 60 & $1.9 \%$ \\
\hline Open Textbook & 53 & $1.7 \%$ \\
\hline Simulation & 49 & $1.5 \%$ \\
\hline Presentation & 26 & $0.8 \%$ \\
\hline Drill and Practice & 24 & $0.8 \%$ \\
\hline Workshop and Training Material & 10 & $0.3 \%$ \\
\hline Learning Object Repository & 7 & $0.2 \%$ \\
\hline Tutorial & 5 & $0.2 \%$ \\
\hline Case Study & 2 & $0.1 \%$ \\
\hline Quiz/Test & 2 & $0.1 \%$ \\
\hline Assessment Tool & 1 & $0 \%$ \\
\hline Development Tool & 1 & $0 \%$ \\
\hline Social Networking Tool & 0 & $0 \%$ \\
\hline Total & 3192 & $100 \%$ \\
\hline
\end{tabular}


The learning objects presented in the MAOR repository are intended for different audiences, but mainly for higher education and professional training (2122 objects oriented toward higher education; 1718 toward professional training). In many cases, an object is intended for more than one target audience. Table 3 presents the distribution of learning objects according to target audiences. It is important to note here that MAOR reflects the Israeli education system norms, in which the "college" level in fact refers to undergraduate studies; the break into Upper and Lower Divisions is not practiced in Israel.

Table 3: Learning object distribution according to target audiences

\begin{tabular}{|l|r|}
\hline \multicolumn{1}{|c|}{ TARGET AUDIENCE } & NUMBER OF LEARNING OBJECTS \\
\hline Higher education & 2122 \\
\hline Professional training & 1718 \\
\hline Middle School & 893 \\
\hline High school & 606 \\
\hline Grade School & 304 \\
\hline
\end{tabular}

Table 4 presents learning object distribution according to technical format. Data reveals that most learning objects are in video format (1614 objects, $50.6 \%$ of all learning objects) and HTML/Text (1038 objects, $32 \%$ of all learning items). Format in this case refers to the format of the page directly linked from MAOR; some HTML/Text objects may in addition contain video, audio, or other files which are catalogued in additional notes. However, very few objects enable interactivity (user-interface) with immediate feedback (e.g. Java applets with only $2.9 \%$ ).

\section{Table 4: Learning object distribution according to technical format}

\begin{tabular}{|l|r|r|}
\hline \multicolumn{1}{|c|}{ TECHNICAL FORMAT } & $\begin{array}{c}\text { NUMBER OF } \\
\text { LEARNING OB- } \\
\text { JECTS }\end{array}$ & $\begin{array}{c}\text { PRESENTAGE OF } \\
\text { ALL LEARNING } \\
\text { OBJECTS }\end{array}$ \\
\hline Video & 1614 & $50.6 \%$ \\
\hline HTML/Text (+PPT+PDF+DOC) & 1038 & $32.5 \%$ \\
\hline Other & 244 & $7.6 \%$ \\
\hline Java Applet & 91 & $2.9 \%$ \\
\hline Image & 46 & $1.4 \%$ \\
\hline Flash & 43 & $1.3 \%$ \\
\hline Audio & 4 & $0.1 \%$ \\
\hline Unknown & 112 & $3.5 \%$ \\
\hline Total & $\mathbf{3 1 9 2}$ & $\mathbf{1 0 0 \%}$ \\
\hline
\end{tabular}

\section{The Expansion Rate of MAOR Repository}

Addressing the second question of the study, which deals with the growth rate of the number of learning objects in the repository, findings will be presented in two figures. First, learning object publishing rate will be displayed according to the day in which each object was published (Figure 
1). Second, a descriptive measure of the process, which is the number of learning objects that joined the repository during the last two and a half years, will be presented (Figure 2).

Figure 1 shows that objects were contributed to the repository continuously from the moment of its establishment to this day. However, it seems that in May 2010 a particularly large number of resources were contributed to the repository (using auto run mechanism).

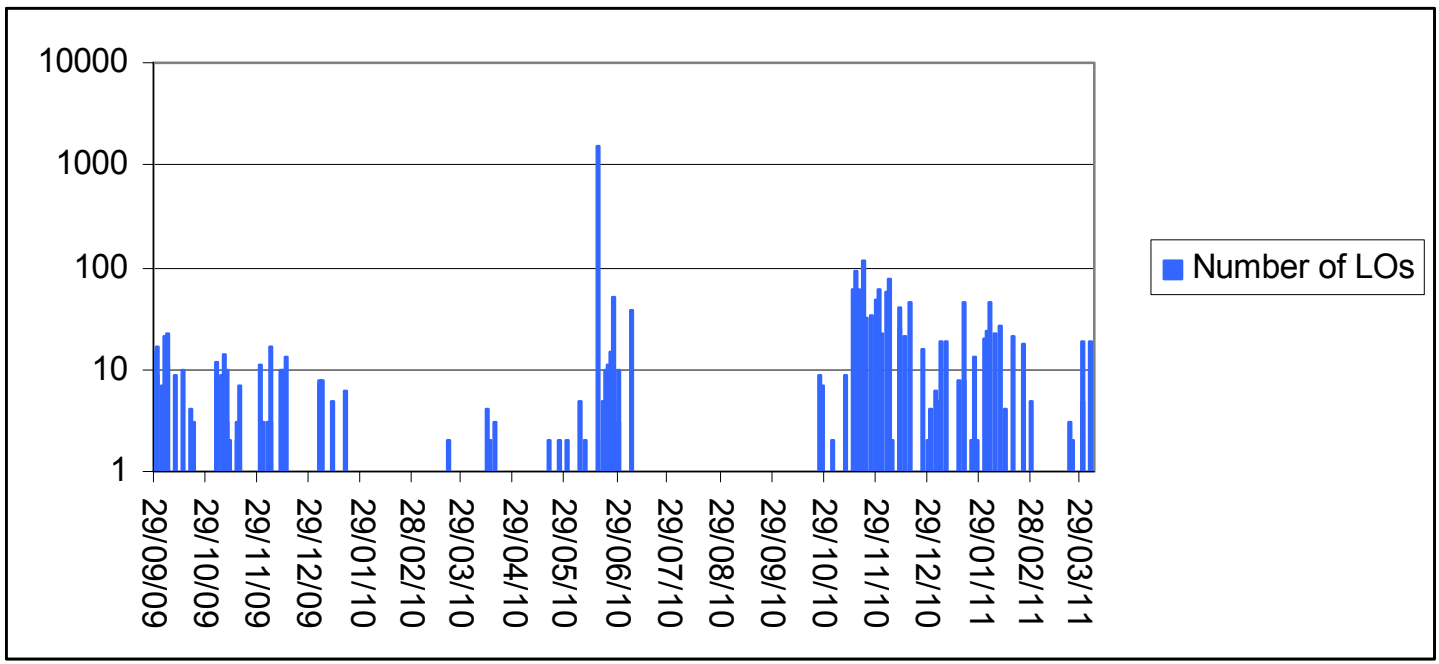

Figure 1: Learning Objects (Los) according publication day.

The descriptive measure of the process is the number of learning objects that were added to the repository during the last two and a half years. Figure 2 presents the number of learning objects that were published in MAOR by four-month periods (the bar graph) and the cumulative number of the learning objects, which indicate the growth rate of the repository (the line graph).

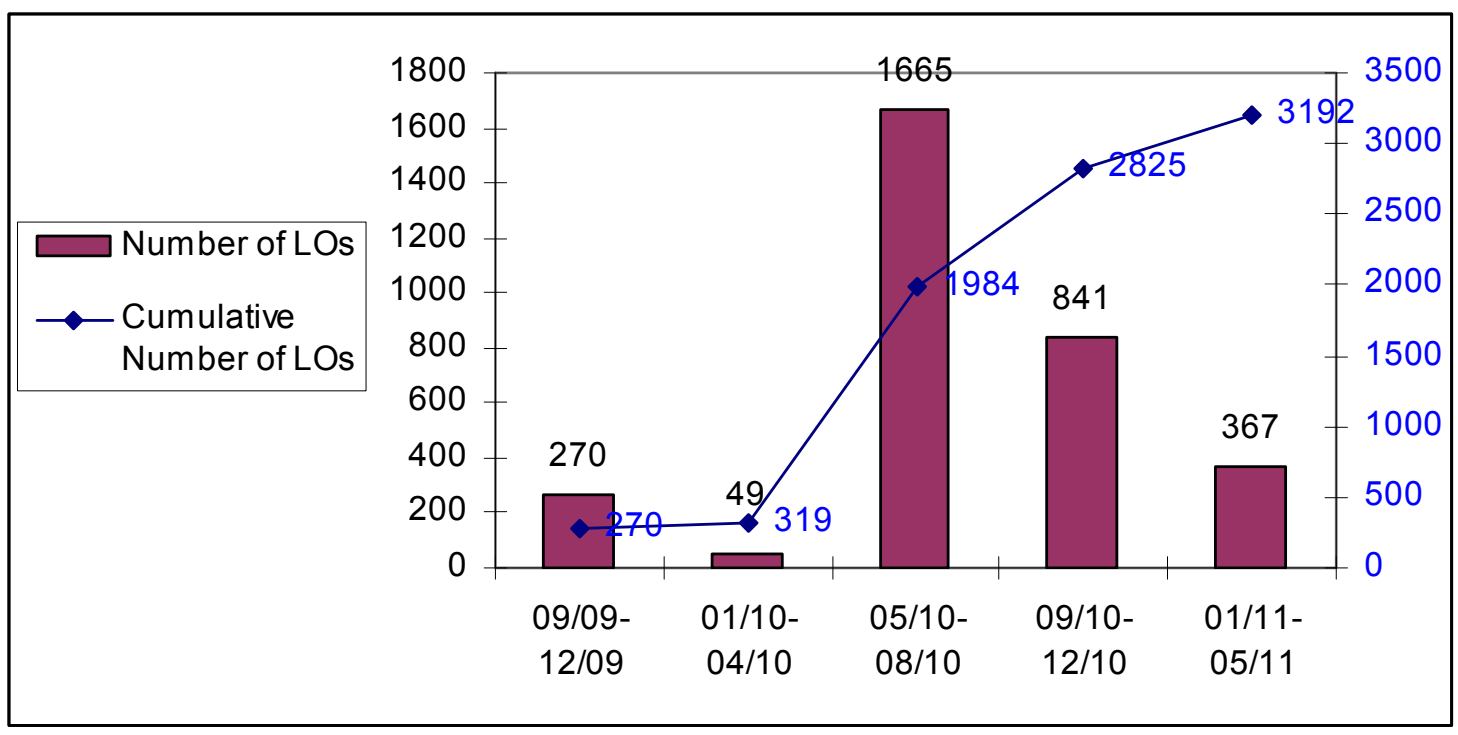

Figure 2: Number and Cumulative Number of Learning Objects (LOs) were published in periods of time.

The graph indicates (through the cumulative number) that the number of learning objects in MAOR has increased more than tenfold over the two and a half years period: from 270 learning 
objects in 09/2009-12/2009 to 3192 learning objects in 01/11-.5/11. The graph also shows that contributions to the repository are consistent over time. It should be noted that here again the large number of resources that were contributed to the repository in May are presented in this graph.

\section{The Contributors}

Addressing the third question of the study, data about the contributors were extracted. Table 5 shows that the contributors were mainly educational institutions, particularly academia (Haifa University, The Open University, Tel Aviv University, and The Hebrew University of Jerusalem) and content providers - mainly the Center for Educational Technology (CET) in Israel. However, some few contributors were defined as individual users. These findings reflect the significant activities that were carried out in the stage of MAOR development to encourage the contribution of learning materials by higher education institutions and content providers.

\begin{tabular}{|c|c|}
\hline \multicolumn{2}{|c|}{ Table 5: Contributors distribution } \\
\hline CONTRIBUTOR & NUMBER OF LEARNING OBJECTS \\
\hline Israeli Universities & 1670 \\
\hline Content Providers & 901 \\
\hline Israeli Research Institutes & 349 \\
\hline Individuals & 105 \\
\hline Schools (K-12) & 78 \\
\hline Health Organizations & 43 \\
\hline European and American Universities & 24 \\
\hline European and American Research Institutes & 10 \\
\hline Israeli Colleges & 9 \\
\hline European and American Colleges & 3 \\
\hline Total & 3192 \\
\hline
\end{tabular}

Most of the contributors published their own materials: about $90 \%$ of the learning objects were published by their authors. Only about $10 \%$ of the learning objects were published by users that were not recognized as the learning objects' authors (Table 6).

\begin{tabular}{|l|r|r|}
\hline \multicolumn{3}{|c|}{ Table 6: Authors distribution } \\
\hline & $\begin{array}{c}\text { NUMBER OF } \\
\text { LEARNING } \\
\text { OBJECTS }\end{array}$ & $\begin{array}{l}\text { PRESENTAGE OF } \\
\text { ALL LEARNING } \\
\text { OBJECTS }\end{array}$ \\
\hline Published by the authors & 2880 & $90.2 \%$ \\
\hline Published not by the authors & 312 & $9.8 \%$ \\
\hline Total & $\mathbf{3 1 9 2}$ & $\mathbf{1 0 0 \%}$ \\
\hline
\end{tabular}




\section{Discussion}

This paper presented a learning object repository, MAOR, guided by the ideas of sharing, openness and community suited to the Web 2.0 era (Hylén, 2006; World Forum of UNESCO Chairs," 2002), in which the community is involved in the processes of creation, evaluation and distribution (Monge et al., 2008; Sicilia et al., 2010). MAOR was established on the basis of the global trend toward openness and collaboration in international consortiums such as the GLOBE, which facilitate connections among portals and allow for an expanded search between repositories and enable a near unlimited flexibility of educational possibilities suited to varied users and needs. MAOR is accessible to all educational institutions, includes diverse and accessible learning objects, and provides tools for searching and locating objects to be used in various learning frameworks. All these indicate that the trend of sharing and retrieval of learning materials is a broad trend, evolving in different directions by many different audiences of content developers and users.

Today, institutions and organizations such as MIT, Globe, MERLOT, and others are offering a wide range of free learning materials online, contrary to the policy that was acceptable to universities and institutions of education not long ago (Abelson, 2008; Malloy \& Hanley, 2001; Nachmias et al., 2007; Taylor, 2007). In the recent years, as reflected in MAOR repository, the growing trend in educational institutions is to share a variety of learning materials from different disciplines with diverse audiences, allowing efficient reuse of learning objects. MAOR fits in the current global trends of sharing and retrieving materials, through which multiple content developers offer learning materials created by them to the public free of charge. These learning materials provide a strategic opportunity to improve the quality of education as well as facilitate policy dialogue, knowledge sharing, and capacity building. Instructors may integrate objects according to specific pedagogical demands, fill in information, and construct new learning processes tailored to the needs of different target audiences. As a result, instructors, learners, and international content providers form communities that share learning materials. Materials can be exchanged and expanded substantially through using basic meta-data to characterize objects.

This paper presents preliminary findings, which provide information about the characteristics of learning objects in MAOR. Varied types of learning objects were found, representing different types of content and activities with different aims and goals aimed at variant target audiences. MAOR log files show that at this stage, MAOR offers more than 3,000 objects in various disciplines, including the Humanities, Social Sciences, Science and Technology, Arts, Education, and Economics. The repository features a variety of types of content and activities applying to various educational goals, such as Reference Material, Collection, Online Course, Open Textbook/Journal/Article, Assignment, Presentation, Recorded Lesson, Simulation, and Social Networking Tool. Even though this study focuses on materials that have been cataloged through the MAOR portal, as a result of international collaboration and connection to other portals, the MAOR community enjoys access to a further variety of learning objects. As partners in the MERLOT repository, the community enjoys a dynamic and expanding collection containing 28,051 materials contributed by 94,052 members (MERLOT, 2011). Connection to the international Globe consortium expands access substantially to about 800,000 materials in other consortiums (Globe, 2011).

The use of the MAOR repository has become substantial and continues to rise every year. The majority of resources were contributed by educational institutions, mainly academic institutions and content providers. However, we can also see some contributions by the Ministry of Education and the general public. Most of the institutions and content providers were recognized as the authors of the learning objects that they have published, in contrast with findings by similar repositories that store only the meta-data and not the contents themselves, such as MERLOT. Although MOAR was established on the basis of the MERLOT model, in MERLOT, only about $2 \%$ of the 
contributors were recognized as the authors of the learning objects contributed. The significantly higher number of contributors than authors is relevant as it points out that MERLOT is more a community of contributors than of authors (Sicilia et al., 2010). However, the fact that the most of the content providers in MAOR were recognized as the authors is probably the result of one of the main goals of MAOR being to encourage institutions to publish their own learning materials in order to promote collaboration and the reuse of existing digital learning material among academic institutes, universities, colleges, and schools in Israel.

Israeli institutions (academic and content developers) and individuals follow the international trend: they are willing to contribute their learning materials and share them with their peers, and see themselves as part of a wider learners' community. Furthermore, our findings indicated that many institutions consider the contribution of materials to be part of the institution policy and not a one-time event. At least two institutions have contributed a significant part of the learning materials available online due to the declared policy of the institution. In contrast, institutions that have not yet consolidated a policy to contribute materials do not (currently) offer a significant amount of open materials. Findings further indicate that the scope of contribution by individuals in the community is very small. However, we believe that this audience would fit the general trend and contribute to the shared repository. It should be noted that, at this stage of MAOR's development, significant activities to encourage individual's contribution were not performed as they were with higher education providers and content providers.

Many online repositories that offer learning materials, whether there are closed or open, require the user to perform a local search, by that significantly limiting the search scope and the amount of time required for locating learning resources. MAOR is a portal to local and international repositories of digital learning objects, such as MERLOT, and contains information about objects (meta-data) only. In addition, MAOR is part of an international consortium enabling connections between portals, part of the international community for the exchange of learning materials. Accordingly, MAOR enables organizations and institutions to establish a local repository of learning materials that suit the specific and unique needs of each institution, while still sharing materials with the global learners' community as a part of the MAOR portal. MAOR intends to improve its search method, being a portal that contains metadata (data about learning objects) which is stored in many other online repositories. The meta-data that were previously entered according to the ISRACore allowed characterization, detection and retrieval of an object based on keywords, object description, target audience etc., along with cost-effective utilization of national or private resources (Bar-Ilan, 2008). Describing the object through meta-data helps users examine the suitability of the object to their needs and enables the combination of multiple objects into a new learning unit. The establishment of the Israeli standard has created a common language for the community of content developers, contributing to the ability to share information between learners' communities with greater ease and according to shared criteria for the definition of learning objects. The standard additionally allows users to search for materials in different repositories linked only by the use of a common language and to integrate that description in MAOR. In this way, MAOR greatly expands the ability to retrieve and use learning materials. Combining objects from different sources helps create a variety of learning processes, which enrich the subject of study, improve teaching quality, and increase pedagogical and economical efficiency in Israel's institutes of learning (Reisman, 2009). In this context, the contribution of MAOR to the efficiency of the search method should be examined in future research.

\section{Conclusion}

This paper contributes to the body of knowledge accumulated on global learning object repositories in the age of Open Access (Open Educational Resources). It presents preliminary findings of the MAOR repository. However, further monitoring MAOR's development and exploring its 
benefits and contribution to learning communities over time is still being researched. Also, the usage of MAOR from the perspectives of the community, both contributors and consumers, will need to be addressed in future work. In further research, at least three more significant issues need exploring regarding the usage of the MAOR repository. The first is meta-data usage in MAOR and its contribution for the process of learning objects retrieval, reuse and re-construction of learning materials, and its maintenance in the capability of transferring information among repositories. The second is the copyright issue. Although many academics and institutions are willing to share their work, it is not unusual that authors like to retain some rights over their work.

Several open content licenses have been developed, such as Creative Commons, to accommodate the problem of copyright and ownership of the materials (Friesen, 2009; Yuan, MacNeill, \& Kraan, 2008). Further research will explore the use of copyright license by the community as it is displayed in the meta-data fields specific to this issue. The third is the ability of MAOR to provide tools and possibilities for personal expression in an open, global public space, which is crucial, since the personal spaces allows users to construct, preserve, and present knowledge in a way uniquely suited to their individual patterns of use by utilizing technological tools to mark materials, such as tags, bookmarks, and personal collections. In order to accomplish these studies, it is necessary to further the development of the data mining tool that was used in this research to extract the relevant data regarding MAOR and it usage.

\section{References}

Abelson, H. (2008). The creation of OpenCourseWare at MIT. Journal of Science Education and Technology, 17(2), 164-174.

Bar-Ilan, Y. (2008). Israeli standard for learning material - ISRACore. Proceeding of the $6^{\text {th }}$ annual conference of Meital, Haifa University, Israel.

Barker, P., \& Campbell, L.M. (2010). Metadata for learning materials: An overview of existing standards and current developments. Technology, Instruction, Cognition and Learning, 7(3-4), 225-243.

Cechinel, C., Sanchez-Alonso, S., \& Garcia-Barriocanal, E. (2011). Statistical profiles of highly-rated learning objects. Computers \& Education, 57(1), 1255-1269.

Dahl, O. J., \& Nygaard, K. (1966). SIMULA - An ALGOL based simulation language. Communications of the ACM, 9(9), 671-678.

The Directory of Open Access Repositories - OpenDOAR. (2011). Growth of the OpenDOAR Database Worldwide. Retrieved August 15, 2011 from http://www.opendoar.org/find.php?format=charts

Downes, S. (2007). Models for sustainable open educational resources. Interdisciplinary Journal of Knowledge and Learning Objects, 3, 29-44. Retrieved from http://www.ijello.org/Volume3/IJKLOv3p029044Downes.pdf

Duncan, C. (2003). Digital repositories: e-Learning for everyone. Presented at eLearn International, 9-12 February, Edinburgh.

Foster, N. F., \& Gibbons, S. (2005). Understanding faculty to improve content recruitment for institutional repositories. D-Lib Magazine, 11(1). Retrieved from http://www.dlib.org/dlib/january05/foster/01 foster.html

Friesen, N. (2009). Open educational resources: New possibilities for change and sustainability. The International Review of Research in Open and Distance Learning, 10(5), 1-13.

GLOBE, (2011). Metadata Analysis Report: GLOBE Member Repositories. Internal report.

Hylén, J. (2006). Open educational resources: Opportunities and challenges. Retrieved August 18, 2011 from http://www.oecd.org/dataoecd/5/47/37351085.pdf

The JORUM Team. (2006). E-learning repository systems research watch. Project Document. 
Malloy, T. E., \& Hanley, G. L. (2001). MERLOT: A faculty-focused Web site of educational resources. Behavior Research Methods, Instruments, \& Computers, 33(2), 274-276.

MAOR. (2011) Meta-data and Object Repository website [On-line]. Available at http://maor.iucc.ac.il/

MERLOT. (2011). Multimedia educational resource for learning and on-line teaching website [On-line]. Available at http://www.merlot.org/

Monge, S., Ovelar, R., \& Azpeitia, I. (2008). Repository 2.0: Social dynamics to support community building in learning object repositories. Interdisciplinary Journal of E-Learning and Learning Object, 4, 191-204.

Nachmias, R., Leiba, M., \& Ram, J. (2007). European Virtual N2L University (EVNU) - Educational exchange in Nano2Life - A network of excellence. Paper presented at the EDEN 2007 annual conference - NEW LEARNING 2.0? Emerging digital territories developing continuities New divides, Italy.

Nash, S. S. (2005) Learning objects, learning objects repositories, and learning theory: Preliminary best practices for online courses. Interdisciplinary Journal of Knowledge and Learning Objects, 1, 217-228. Retrieved August 18, 2011 from http://ijklo.org/Volume1/v1p217-228Nash.pdf

Reisman, S. (2009). Using learning objects to affect educational outcomes. Computer, 42(8), 102-104.

Schell, G. P., \& Burns, M. (2002). Merlot: A repository of e-learning objects for higher education. $e$ Service Journal, 1(2), 53-64.

Shmueli, E., \& Cohen, A. (2011). The usage of open educational resources in MAOR repository. Manuscript submitted for publication.

Shmueli, E., Reisman, S., \& Sperling, B. (2010). The new learning communities: MAOR - The Israeli learning object repository. Emerging Technologies for Online Learning. Retrieved May 20, 2011 from http://sloanconsortium.org/et4online/maor-israeli-learning-object-repository

Sicilia, M., García-Barriocanal, E., Sánchez-Alonso, S., \& Cechinel, C. (2010). Exploring user-based recommender results in large learning object repositories: The case of MERLOT. Procedia Computer Science, 1, 2859-2864.

Taibi, D., Gentile, M., \& Seta, L. (2005). A semantic search engine for learning resources. Paper presented at the Third International Conference on Multimedia and Information \& Communication Technologies in Education.

Tal-Elhasid, E., Yair, Y., \& Meishar-Tal, H. (2009). "Open Books": Free opening of academic e-books, audio-books and educational resources at The Open University of Israel: Lessons from the first year. Paper presented at E-society 2009, IADIS International Association for Development of the Information Society, Barcelona, Spain.

Taylor, J. C. (2007). Open courseware futures: Creating a parallel universe. E-Journal of Instructional Science and Technology, 10(1), 1-9.

Wiley, D. A. (2000). Connecting learning objects to instructional design theory: A definition, a metaphor, and a taxonomy. In D. A. Wiley (Ed.), The instructional use of learning objects: Online version. Retrieved January 15, 2007 from http://reusability.org/read/chapters/wiley.doc

World Forum of UNESCO Chairs (2002). Proposal for launching the "Academics across Borders" initiative, Paris. Retrieved May 20, 2011 from http://portal.unesco.org/education/en/file_download.php/ba88fefb95a301b90e6395044552516baab_do c 2002.pdf

Yuan, L., MacNeill, S., \& Kraan, W. (2008). Open educational resources-Opportunities and challenges for higher education. Retrieved May 20, 2011 from http://digitalcommons.bolton.ac.uk/cgi/viewcontent.cgi?article=1000\&context=iec reports\&sei$\underline{\text { reir }=1 \# \text { search }=" O p e n+\text { educational }+ \text { resourcesâOpportunities }+ \text { and }+ \text { challenges }+ \text { for }+ \text { higher }+ \text { education }}$ 


\section{Biographies}

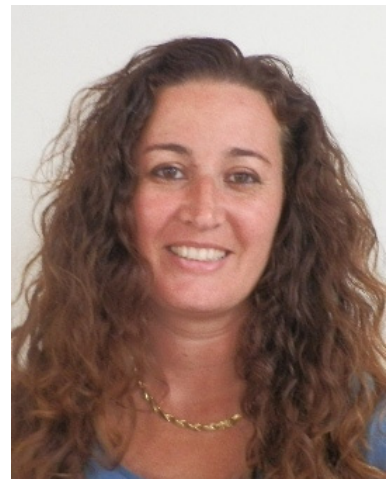

Anat Cohen is a researcher and a lecturer in Tel-Aviv University's School of Education. Her Ph.D dissertation analyzed the costeffectiveness of Web-based Education, based on theoretical and computational models and empirical data using web-mining techniques. She participated in the IEA's Second International Technology in Education Study (SITES) and is currently a research and pedagogical coordinator of Virtual TAU - Web-Supported Academic Instruction in Tel-Aviv University. She has published over 20 research papers in leading peer-reviewed journals and conference proceedings. Her major research areas are: Cost-Effectiveness of Web-based Learning, Learning object repositories, Ubiquitous Learning, ICT implementation in Higher Education, Educational Data-Mining.

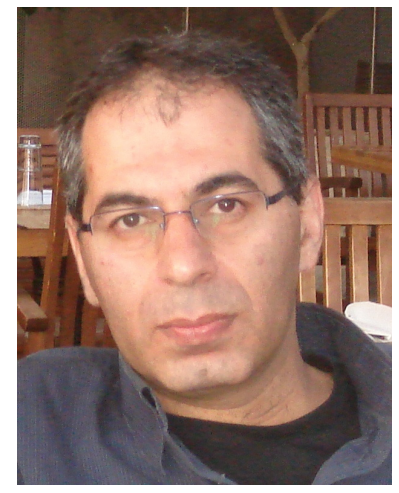

Eli Shmueli is MEITAL director, the Inter-University Centre for eLearning (IUCEL), which is part of the Israeli Inter-University Computation Centre (IUCC). MEITAL assists and promote Israeli institutions of higher education - universities and academic colleges - in advancing the use of e-learning technologies and creates opportunities for connection and collaboration between them. HE is a Graduate student in Tel-Aviv University's School of Education. Eli leads MAOR project, the Israeli learning object meta-data repository. Recently he received on behalf of Meital a reward form MERLOT for his activity in MAOR and its contribution to the worldwide community. His major specialities are: Advanced Learning technologies, Learning object repositories, Metadata standards, ICT implementation in Higher Education.

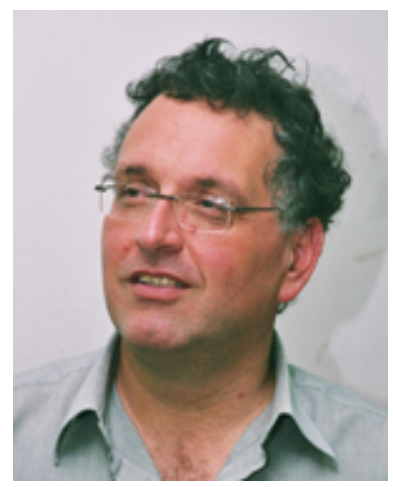

Rafi Nachmias is the deputy head of Tel Aviv University's School of Education. Since the year 2000 he is heading the Science and Technology Education Centre (SATEC), the Sciences Education program and the Virtual TAU project in Tel Aviv University. Professor Nachmias was the National Research Coordinator of the in IEA's Second International Technology in Education Study (SITES) and the TIMSS study. He was a member of FP6 Nano2Life EU network of excellence and currently participates in EU's FP7 Dynalearn project on the implementation of innovative IT tools in academic instruction. He has published five books on ICT in Education, Web based learning and Science Education; over 80 research papers in leading peer reviewed journals, and over 100 papers in professional international conference proceedings.

His major research areas are: Web-based Learning, Educational Data Mining, Web-based academic instruction, Innovative pedagogical practices using ICT and Mathematics and Science education. 